\title{
Rubidium and potassium levels are altered in Alzheimer's disease brain and blood but not in cerebrospinal fluid
}

\author{
Blaine R. Roberts ${ }^{1,2^{*}}$, James D. Doecke ${ }^{2,3,4}$, Alan Rembach ${ }^{1 \wedge}$, L. Fernanda Yévenes ${ }^{1}$, Christopher J. Fowler ${ }^{1}$, \\ Catriona A. McLean ${ }^{1,5,6}$, Monica Lind ${ }^{1}$, Irene Volitakis ${ }^{1}$, Colin L. Masters ${ }^{1,2}$, Ashley I. Bush ${ }^{1,2}$, Dominic J. Hare 1,7 $^{1,7}$ \\ and the AIBL research group ${ }^{8}$
}

\begin{abstract}
Loss of intracellular compartmentalization of potassium is a biochemical feature of Alzheimer's disease indicating a loss of membrane integrity and mitochondrial dysfunction. We examined potassium and rubidium (a biological proxy for potassium) in brain tissue, blood fractions and cerebrospinal fluid from Alzheimer's disease and healthy control subjects to investigate the diagnostic potential of these two metal ions. We found that both potassium and rubidium levels were significantly decreased across all intracellular compartments in the Alzheimer's disease brain. Serum from over 1000 participants in the Australian Imaging, Biomarkers and Lifestyle Flagship Study of Ageing (AIBL), showed minor changes according to disease state. Potassium and rubidium levels in erythrocytes and cerebrospinal fluid were not significantly different according to disease state, and rubidium was slightly decreased in Alzheimer's disease patients compared to healthy controls. Our data provides evidence that contrasts the hypothesized disruption of the blood-brain barrier in Alzheimer's disease, with the systemic decrease in cortical potassium and rubidium levels suggesting influx of ions from the blood is minimal and that the observed changes are more likely indicative of an internal energy crisis within the brain. These findings may be the basis for potential diagnostic imaging studies using radioactive potassium and rubidium tracers.
\end{abstract}

\section{Introduction}

Mitochondrial dysfunction and impaired energy metabolism are features that immediately precede neuronal loss in Alzheimer's disease (AD) [1]. Oxidative stress arising from neurotoxic $\beta$-amyloid $(A \beta)$ accumulation and oligomerization causes a loss in membrane integrity in the synapse [2], which is heavily dependent on sufficient ATP production to regulate ion transport in and out of the cell [3]. Oligomeric A $\beta$ species adversely affect cellular function through a range of hypothesized mechanisms, a number of which directly compromise both energy production and membrane potential $[4,5]$.

Impaired energy production related to $\mathrm{AD}$ pathology has been of research interest. Positron emission tomography

\footnotetext{
* Correspondence: blaine.roberts@florey.edu.au

Deceased

${ }^{1}$ The Florey Institute of Neuroscience, The University of Melbourne, Parkville, VIC, Australia

${ }^{2}$ Cooperative Research Centre for Mental Health, Parkville, VIC, Australia

Full list of author information is available at the end of the article
}

(PET) has identified a metabolic decrease in glucose consumption in the AD brain [6], which is indicative of reduced neural activity [7] and direct impairment of $\mathrm{Na}^{+} / \mathrm{K}^{+}$-ATPase-regulated intramembrane ion transport [8]. Thus, there is potential that markers of modified $\mathrm{K}^{+}$handling may be indicative of $\mathrm{AD}$, and could be a useful preclinical marker of increased AD risk.

As a group 1 alkali metal, rubidium $\left(\mathrm{Rb}^{+}\right)$has similar biochemical characteristics to $\mathrm{K}^{+}$[9]. Though it has no known biological function, $\mathrm{Rb}^{+}$is present in almost all biological systems due to its ability to readily exchange with $\mathrm{K}^{+}[10]$. Assessment of $\mathrm{Rb}^{+}$is a useful proxy for $\mathrm{K}^{+}$, so much so that turnover of radioactive ${ }^{86} \mathrm{Rb}^{+}$has been successfully used as a measure of basal metabolic rate [11]. Rubidium assays are also less prone to environmental contamination, and the ion is present in biological matrices at concentrations well suited to contemporary analytical techniques [12]. 
As is the case with many other biometals, there are numerous conflicting reports of either changes to [13, 14] or stability of [15-17] $\mathrm{Rb}$ and $\mathrm{K}$ levels in $\mathrm{AD}$, most likely due to low statistical power. Here, we used post mortem brain tissue from the Victorian Brain Bank Network along with blood samples from the Australian Imaging, Biomarkers and Lifestyle Flagship Study of Ageing [18], which is one of the world's largest longitudinal studies of $\mathrm{AD}$, to investigate changes in the regulation of $\mathrm{K}^{+}$ and $\mathrm{Rb}^{+}$from a system-wide perspective. We aimed to categorically determine if levels of these metals are altered in AD.

\section{Methods and materials}

\section{Human brain samples}

All brain tissues were obtained from the Victorian Brain Bank Network, and all experiments were approved by the University of Melbourne health sciences, human ethics subcommittee (ID1136882). Tissue was collected at autopsy, frozen at $-80{ }^{\circ} \mathrm{C}$, then thawed to $-20{ }^{\circ} \mathrm{C}$ and sectioned into $1 \mathrm{~cm}$ slices. From these, c.a. 5 g samples of frontal cortex were collected and $0.5 \mathrm{~g}$ aliquots of grey matter dissected and stored at $-80{ }^{\circ} \mathrm{C}$ until analysis. Neurological control tissues were defined as free from $\mathrm{AD}$ lesions with the number of plaque and tangles were well below the cut-off values for the neuropathological diagnosis of AD (NIA Reagan criteria). No other neurological disease was present.

\section{Preparation of tissue homogenate fractions}

Sample preparation steps for tissue samples were adapted our previously reported methods $[19,20]$. Aliquots $(0.1-0.3 \mathrm{~g})$ of dissected grey matter from the frontal cortex were thawed on ice and homogenized in singleuse BioMasher (Omni International) vials. After centrifugation at $100,000 \mathrm{~g}$ a $1: 4$ tissue-to-buffer $(\mathrm{w} / \mathrm{v})$ ratio of Tris buffered saline (TBS; $50 \mathrm{mM}$ Tris, $\mathrm{pH}$ 8.0, $150 \mathrm{mM}$ $\mathrm{NaCl}$ ) with EDTA-free protease inhibitors (Roche) was added to each homogenate. Samples were transferred to ultracentrifuge vials, spun at $100,000 \mathrm{~g}$ for $30 \mathrm{~min}$ at $4{ }^{\circ} \mathrm{C}$, and then had the supernatant removed (the 'soluble' fraction). The remaining pellet was isolated and resuspended with 1:4 (w/v) $100 \mathrm{mM} \mathrm{NaCO}_{3}(\mathrm{pH}$ 11.0), then centrifuged again at $100,000 \mathrm{~g}$ for $30 \mathrm{~min}$ at $4{ }^{\circ} \mathrm{C}$ to retrieve the 'vesicular' fraction. Remaining material was then subjected to extraction of membrane-bound proteins and metals (the 'membrane' fraction) by addition of $1: 4$ (w/v) $7 \mathrm{M}$ urea, $2 \mathrm{M}$ thiourea, $4 \%$ 3-[(3-cholamidopropyl) dimethylammonio]-1-propanesulfonate (CHAPS) and $30 \mathrm{mM}$ Bicine $(\mathrm{pH} 8.5)$ and further centrifugation at $100,000 \mathrm{~g}$ for $30 \mathrm{~min}$ at $4{ }^{\circ} \mathrm{C}$. Any remaining 'insoluble' material was then digested in $70 \%$ formic acid for c.a. $18 \mathrm{~h}$ before centrifugation as performed for all other extractions. No material remained at the conclusion of fractionation experiments.

\section{Preparation of blood samples}

Protocols for the preparation of serum and erythrocytes was followed according to our previously reported method [21]. Whole blood was drawn from AIBL subjects after overnight fasting. For serum collection, blood was drawn into serum-gel $7.5 \mathrm{~mL}$ tubes (Sarstedt) and left standing at room temperature for $20 \mathrm{~min}$ before centrifugation at $1800 \mathrm{~g}$ for $15 \mathrm{~min}$. Serum was split into $250 \mu \mathrm{L}$ aliquots and stored in liquid nitrogen until analysis. After thawing, serum samples were spun briefly at $1800 \mathrm{~g}$ and diluted 1:10 in $1 \% \mathrm{HNO}_{3}$ for analysis. Platelets were recovered by centrifuging a plasma fraction (collected from whole blood in a lithium-heparin tube) at $800 \mathrm{~g}$ for $15 \mathrm{~min}$ and removing the plasma supernatant.

Erythrocytes were collected from blood samples taken after an overnight fast into standard lithium-heparin $7.5 \mathrm{~mL}$ tubes (Sarstedt). Samples were spun at $3200 \mathrm{~g}$ to remove plasma and platelets, leaving erythrocytes that were washed three times in $0.9 \%(\mathrm{w} / \mathrm{v}) \mathrm{NaCl}$. Erythrocytes were distributed by inverting the tube and then centrifuged at $650 \mathrm{~g}$ for $10 \mathrm{~min}$, after which the supernatant was removed and samples were spun again at $1500 \mathrm{~g}$ for $10 \mathrm{~min}$ at room temperature. Erythrocytes were then resuspended in $6 \mathrm{~mL}$ of $0.1 \mathrm{M}$ PBS and stored in liquid nitrogen until analysis. A $50 \mu \mathrm{L}$ of thawed erythrocytes were transferred to $1.5 \mathrm{~mL}$ polypropylene tubes and digested in equal volumes of $65 \% \mathrm{HNO}_{3}$ and $\geq 30 \%$ $\mathrm{H}_{2} \mathrm{O}_{2}$ on a hotplate at $80{ }^{\circ} \mathrm{C}$. After cooling, samples were diluted 1:20 with $1 \% \mathrm{HNO}_{3}$. Platelets were prepared for analysis using the same digestion procedure as described for erythrocytes.

\section{Preparation of CSF samples}

Cerebrospinal fluid was collected using the gravity drip method described by Rembach et al. [22]. Patients underwent a lumbar puncture procedure following an overnight fast, and up to $8 \mathrm{~mL}$ of CSF was collected directly into a $15 \mathrm{~mL}$ polypropylene tube. Samples were centrifuged at $2000 \mathrm{~g}$ at $4{ }^{\circ} \mathrm{C}$ and then divided into $300 \mu \mathrm{L}$ aliquots and stored on liquid nitrogen. After thawing, $100 \mu \mathrm{L}$ aliquots were diluted $1: 10$ with $1 \%$ $\mathrm{HNO}_{3}$ for analysis.

\section{Rubidium and potassium analysis}

All metal analyses were performed on an Agilent 7700x Series inductively coupled plasma-mass spectrometer (ICP-MS) using a Teflon MiraMist nebulizer (Burgener Research Inc.) and Scott-type double-pass spray chamber (Glass Expansion). Helium was used as a collision gas to remove potential polyatomic interferences. The instrument was calibrated using multi-element standards (Accustandard, ICP-MS-2-1, ICP-MS-3-1, ICP-MS-4-1; total of 44 elements) containing $\mathrm{K}$ and $\mathrm{Rb}$ at $0,5,10,50$, 100 and $500 \mu \mathrm{g} \mathrm{L}^{-1}$ with ${ }^{89} \mathrm{Y}$ introduced online 
through a T-piece as the internal standard. ${ }^{39} \mathrm{~K}$ and ${ }^{85} \mathrm{Rb}$ were monitored. Seronorm ${ }^{\mathrm{Ts}} \mathrm{L} 1$ and L2 (Sero) were reconstituted in $1: 20,1 \% \mathrm{HNO}_{3}$ prior to analysis for use as quality control standards.

\section{Statistical analysis}

All statistical testing was performed in GraphPad Prism v6.0 h using unpaired $t$-tests, one-way ANOVA and Pearson correlation analysis as appropriate. Significance was defined as $p<0.05$ after Bonferroni post-hoc testing.

\section{Results}

$\mathrm{K}$ and $\mathrm{Rb}$ levels are consistently decreased in fractionated brain homogenates

We analyzed post mortem AD and healthy control (HC) frontal cortical tissue $(n=30$ per group, matched for age and sex; see Table 1 for demographics) by subjecting homogenates of frontal cortex to a stepwise fractionation process that extracted material into 'soluble', vesicularperipheral membrane ('vesicular'), membrane-bound ('membrane') and 'insoluble' classifications [19]. These solutions were then assayed for total $\mathrm{K}$ and $\mathrm{Rb}$ content using inductively coupled plasma-mass spectrometry (ICP-MS; see Materials and Methods). In AD frontal cortex significant decreases in both $\mathrm{K}$ and $\mathrm{Rb}$ levels were apparent (Fig. 1a-b). The degree of change increased in magnitude from the 'soluble' to 'insoluble' fractions. As expected, a high degree of correlation between tissue $\mathrm{K}$ and $\mathrm{Rb}$ levels were observed regardless of diagnosis $(r=0.862$ (HC); $r=0.738$ (AD); both $p<$ 0.001; Fig. 1c-d). However, the slope measured by linear regression was significantly decreased in the AD brains $(63.7 \%$ of $\mathrm{HC} ; F=5.41, p<0.05)$. A receiver operating characteristic (ROC) curve of both $\mathrm{K}$ and $\mathrm{Rb}$ levels in the total homogenate (which showed the largest difference between clinical classifications) found that $\mathrm{Rb}$ performed better at predicting $\mathrm{AD}$, with an area under the curve of 0.815 versus 0.754 for K (both $p<0.01$; Fig. 1e-f).

\section{Serum levels of $\mathrm{K}$ and $\mathrm{Rb}$ are altered in Alzheimer's disease}

To investigate whether the observed changes in $\mathrm{K}$ and $\mathrm{Rb}$ levels within brain homogenates are reflected in the

Table 1 Subject demographics for post mortem brain samples

\begin{tabular}{llll}
\hline & $\begin{array}{l}\text { Healthy controls } \\
(n=30)\end{array}$ & $\begin{array}{l}\text { Alzheimer's disease } \\
(n=30)\end{array}$ & $p$ value \\
\hline Age (years) & $76.8(7.6)$ & $78.3(9.2)$ & 0.56 \\
Females (\%) & 33.3 & 26.7 & 0.59 \\
\% APOE ع4 carriers & 13.3 & 75.8 & $<0.001$ \\
$\begin{array}{l}\text { Post mortem interval } \\
\text { (hours) }\end{array}$ & $38.4(14.3)$ & $33.9(21.9)$ & 0.38 \\
\hline
\end{tabular}

Mean (standard deviation); $p$-value calculated using a two-tailed Student's $t$-test periphery, we examined serum $\mathrm{K}$ and $\mathrm{Rb}$ concentrations in the entire baseline AIBL cohort, including the mildly cognitively impaired group $\left(n_{\text {total }}=1077 ; n_{H C}=778\right.$; $n_{M C I}=128 ; n_{A D}=171$; Table 2 ; see Ellis et al. [18] for cohort full demographics). Significant differences were observed for both analytes between $\mathrm{HC}$ and $\mathrm{AD}$ groups, but these shifts did not reflect the magnitude or direction of those observed in the brain. There was a $2.6 \%$ increase in serum $\mathrm{K}$ levels in the AD subjects (Fig. 2a), with a small (5.4\%) decrease in serum Rb (Fig. 2b). There was a highly significant $(p<0.001)$ decrease in the ratio of $\mathrm{Rb}$ to $\mathrm{K}$ in the $\mathrm{AD}$ group (Fig. 2c), though ROC analysis revealed changes in all three measures were less robust (though still statistically significant) indicators of $\mathrm{AD}$ than total $\mathrm{Rb}$ and $\mathrm{K}$ in brain homogenates $\left(\mathrm{AUC}_{K}=\right.$ 0.569; $\mathrm{AUC}_{R b}=0.575 ; \mathrm{AUC}_{R b: K}=0.6115$; Additional file 1: Figure S1). K and Rb levels correlated in both groups, although again to a much lesser extent than in brain homogenates, and the slopes of both lines did not differ $(F=0.21 ; p=0.65$; Fig. $2 \mathrm{~d})$.

\section{$\mathrm{Rb}$ levels are decreased in platelets, but not erythrocytes or CSF}

We analyzed a subset of AD and HC erythrocytes for $\mathrm{Rb}$ and $\mathrm{K}$ concentrations ( $n=40$ per classification) and found no significant difference between groups $(p=0.62$; Fig. 2e, f). K levels in a subset of HC, AD and MCI platelets $\left(n_{H C}=50, n_{A D}=41, n_{M C I}=7\right.$; Table 3$)$ were not different between groups (Fig. 3a). Rb levels in AD platelets were significantly decreased compared to the $\mathrm{HC}$ group (one-way ANOVA; $p<0.05$; Fig. 3b; Table 4). This decrease in $\mathrm{Rb}$ levels in platelets showed limited diagnostic potential when examined using an ROC curve (Additional file 1: Figure S2). In cerebrospinal fluid $\left(\mathrm{CSF} ; n_{H C}=36, n_{A D}=9, n_{M C I}=7\right.$; Table 5$) \mathrm{K}$ and $\mathrm{Rb}$ levels were unaltered according to clinical classification (Fig. 3c, d).

\section{Discussion}

Our results expand upon a previous smaller study that reported decreased $\mathrm{Rb}$ levels in the $\mathrm{AD}$ brain [23]; we found here that $\mathrm{Rb}$ levels are decreased in interstitial/ cytosolic, vesicular, membrane-bound and otherwise insoluble fractions, and that these changes correlate with and reflect decreased $\mathrm{K}$ levels in the same isolates. Both $\mathrm{K}$ and $\mathrm{Rb}$ levels have been shown to be decreased in homogenates from a range of brain regions that show progressive neurodegeneration in $\mathrm{AD}$ [24]. We found no compelling evidence that $\mathrm{K}$ and $\mathrm{Rb}$ levels external to the brain (i.e., blood products and CSF) have diagnostic potential in AD research.

Our data suggests that the observed effects of impaired alkali metal metabolism in the AD brain, such as altered $\mathrm{Na}^{+} / \mathrm{K}^{+}$-ATPase activity manifest as a decrease in 


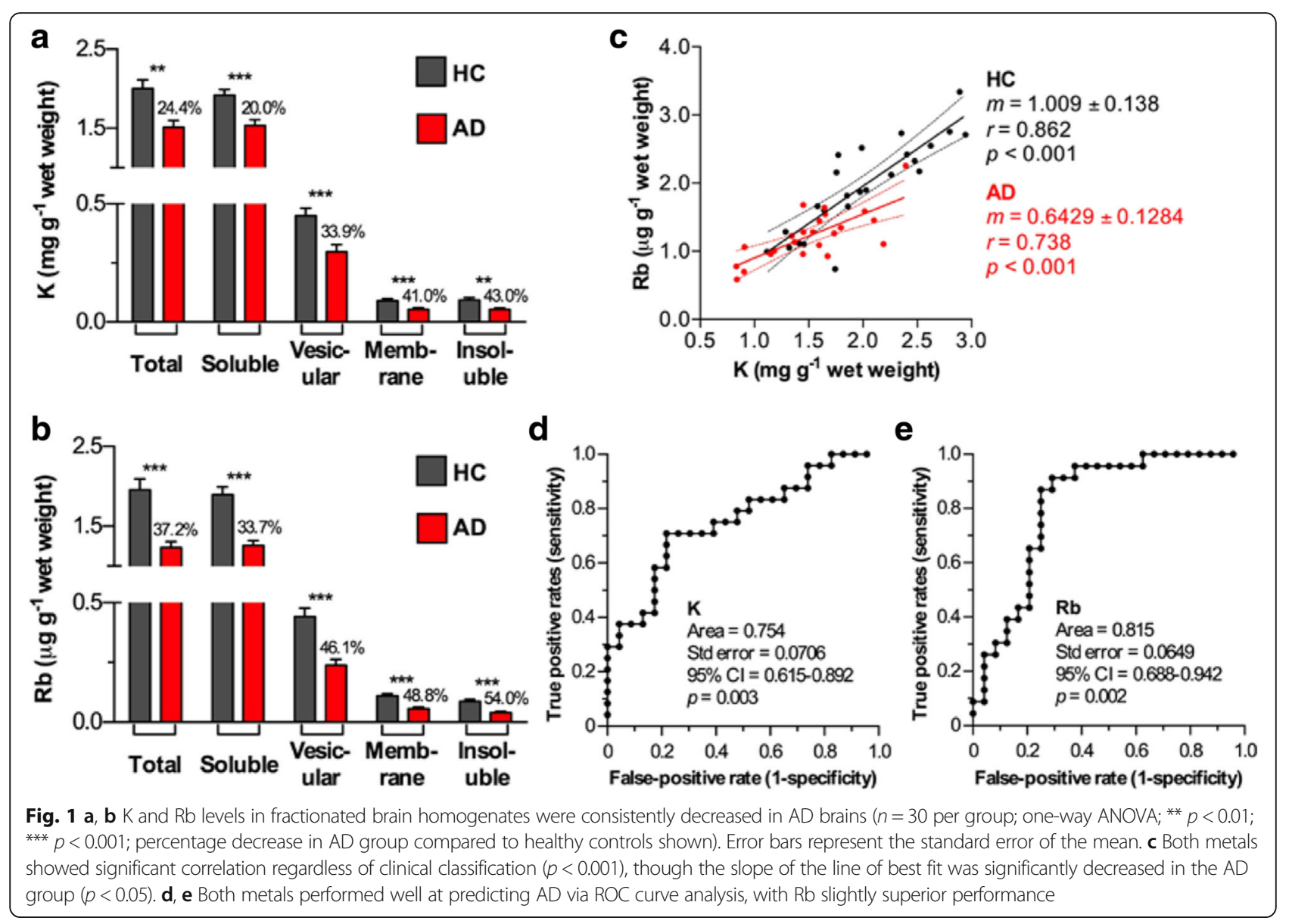

total brain $\mathrm{Rb}$ and $\mathrm{K}$ levels, as opposed to being restricted to a specific fraction. We found that the decrease was of a higher magnitude (c.a. $50 \%$ ) within cellular membranes (i.e., the 'membrane' and 'insoluble' fractions). It is unclear as to whether a reduction in $\mathrm{K}$ (and, by nature of its ability to exchange, $\mathrm{Rb}$ ) is a cause or effect of the disease process, though a number of genes associated with $\mathrm{K}$ transport and flux have been identified as showing decreased

Table 2 Subject demographics of the baseline AIBL cohort used for serum $\mathrm{K}$ and $\mathrm{Rb}$ analysis

\begin{tabular}{lllll}
\hline & $\begin{array}{l}\text { Healthy controls } \\
(n=778)\end{array}$ & $\begin{array}{l}\text { Mild cognitive } \\
\text { impairment } \\
(n=128)\end{array}$ & $\begin{array}{l}\text { Alzheimer's } \\
\text { disease } \\
(n=171)\end{array}$ & $p$-value \\
\hline Age (years) & $70.6(7)$ & $76.2(7.6)$ & $78.8(8.6)$ & $<0.001$ \\
Females (\%) & 57.6 & 56.3 & 62.0 & 0.34 \\
\% APOE & 27.2 & 49.2 & 62.4 & $<0.001$ \\
$\begin{array}{l}\text { E4 carriers } \\
\text { CDR SOB }\end{array}$ & $0.0(0.1)$ & $1.2(0.8)$ & $5.8(2.9)$ & $<0.001$ \\
MMSE & $28.9(1.2)$ & $26.2(2.7)$ & $18.9(5.3)$ & $<0.001$ \\
\hline
\end{tabular}

CDR SOB is the Clinical Dementia Rating Scale Sum of Boxes score used to stage dementia. MMSE is the mini-mental state examination questionnaire score. $p$-value calculated using a one-way ANOVA or chi-squared test for percentages transcription levels in the AD brain [25]. In vitro studies of mixed cortical cultures have shown that $A \beta$ induces $K^{+}$ efflux via enhancing the delayed rectifier $\mathrm{K}^{+}$current $I_{K}$ [26], potentially through the formation of transient ion channels in bilayer membranes [27].

Importantly, this disruption of cellular metabolism in AD likely commences well before the appearance of histopathological features and the onset of clinical symptoms. Genome-wide transcriptomic analysis of AD brains identified as many as $70 \%$ of genes encoding subunits of the mitochondrial electron transport chain were expressed at lower levels in regions of the brain most affected by $\mathrm{AD}$ when compared to controls [28]. Neural network analysis of 'seed genes' (the principal genes from which regulatory pathways are grown [29]) identified those encoding the master energy regulator AMP-activated protein kinase as being dysregulated in AD [30].

The effects of impaired energy metabolism appear to primarily result in a loss of membrane integrity through its negative impact on active transport mechanisms that regulate resting membrane potential. As the major consumer of energy in the cell-maintaining resting potential and action potentials accounts for $20-50 \%$ of energy use in neurons in the cortex [31] - the action of 

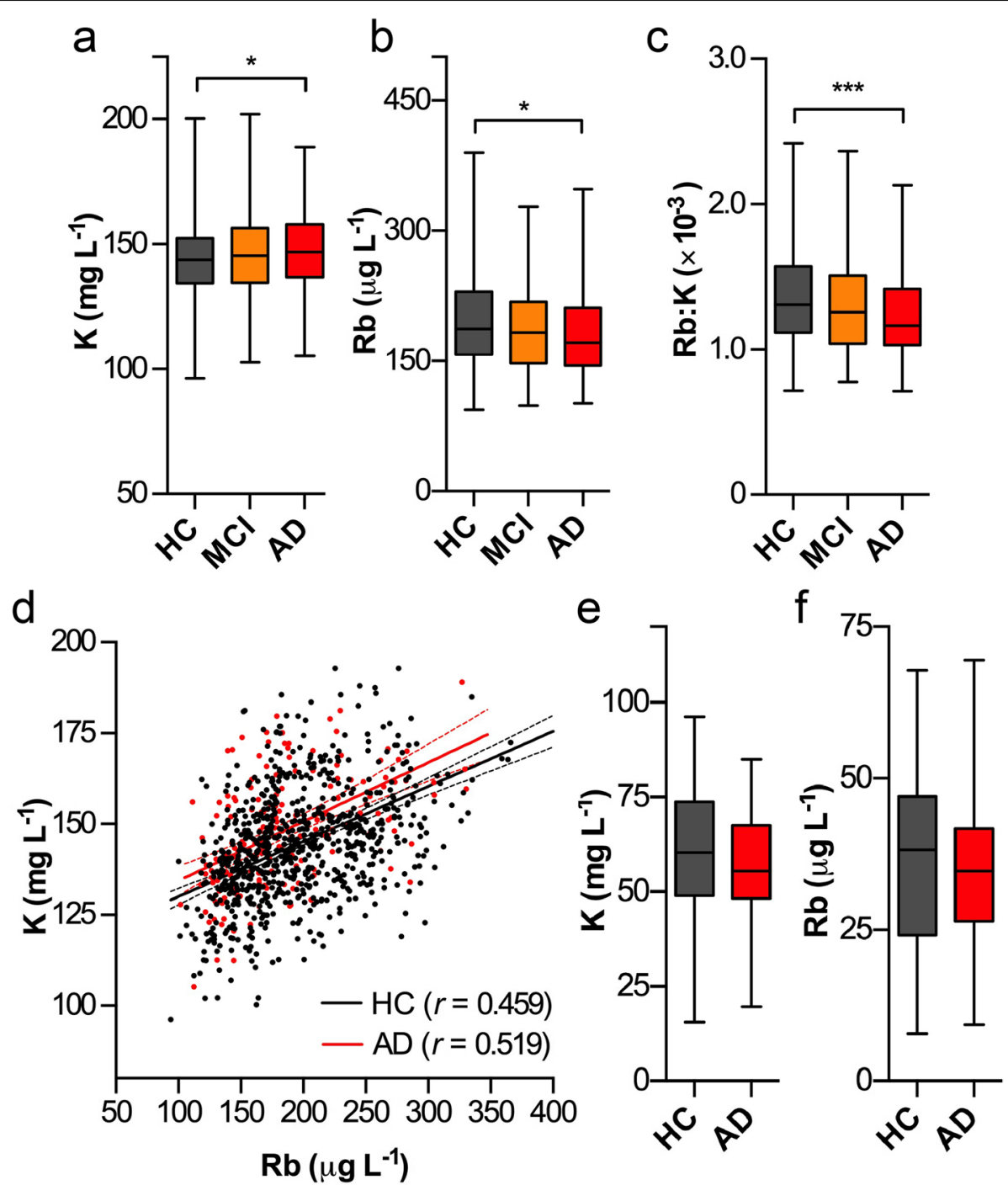

Fig. 2 K levels were significantly increased in AD serum (a; one-way ANOVA; * $p<0.05$ ), whilst Rb levels were conversely decreased in AD $\left(\mathbf{b}\right.$; $\left.{ }^{*} p<0.05\right)$; the latter mirroring our observation in brain homogenates. The ratio of $\mathrm{Rb}$ to K was significantly (*** $\left.p<0.001\right)$ decreased in $\mathrm{AD}(\mathbf{c})$, though $\mathrm{Rb}$ and $\mathrm{K}$ levels were less well correlated in serum (d). In a subset ( $n=30$ per group) of erythrocytes from HC and AD groups, there was no significance difference in metal concentration (e, f). Boxes depict $25^{\text {th }}$ and $75^{\text {th }}$ percentiles and mean; error bars represent minimum to maximum values

$\mathrm{Na}^{+} / \mathrm{K}^{+}$-ATPase is easily compromised by energy deficits. In the $\mathrm{AD}$ brain, $\mathrm{Na}^{+} / \mathrm{K}^{+}$-ATPase activity is depressed [32], with a reduction in $\alpha 3$ subunit mRNA observed, a process that occurs prior to the formation of $A \beta$ plaques and is rapidly accelerated in the disease [33], further supporting the hypothesis that an energy

Table 3 Subject demographics for erythrocytes

\begin{tabular}{llll}
\hline & $\begin{array}{l}\text { Healthy controls } \\
(n=40)\end{array}$ & $\begin{array}{l}\text { Alzheimer's disease } \\
(n=40)\end{array}$ & $p$-value \\
\hline Age (years) & $82.0(8.0)$ & $82.0(8.0)$ & 0.97 \\
Females (\%) & 52.5 & 50.0 & 0.96 \\
\% APOE ع4 carriers & 37.5 & 60.0 & 0.05 \\
\hline
\end{tabular}

$p$-value calculated using a two-tailed Student's $t$-test crisis is inexorably linked to the molecular basis of the disease.

These findings may have diagnostic potential in the clinical setting. Rubidium- 82 has been extensively used in positron emission tomography (PET) as a diagnostic marker for brain tumors [34], with increased uptake of the $\mathrm{Rb}-82$ tracer indicative of a loss of blood-brain barrier (BBB) integrity. Permeability of the BBB is thought to be a feature of both normal aging and $\mathrm{AD}$ [35], though both increased serum $\mathrm{K}$ concentrations in $\mathrm{AD}$ and a failure to identify a change in CSF $\mathrm{K}$ or $\mathrm{Rb}$ levels tends to suggest that $\mathrm{BBB}$ permeability is not directly responsible for the decrease in akali metal levels in the AD brain. Further, a recent study using animal models of $\mathrm{AD}$, including the lipopolysaccharide (LPS) model of induced inflammation, 

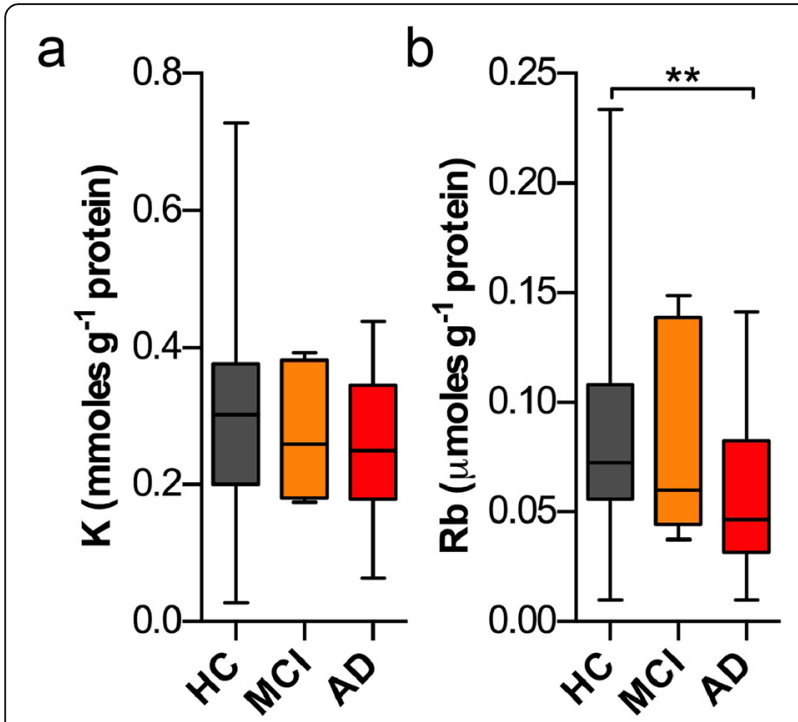

C
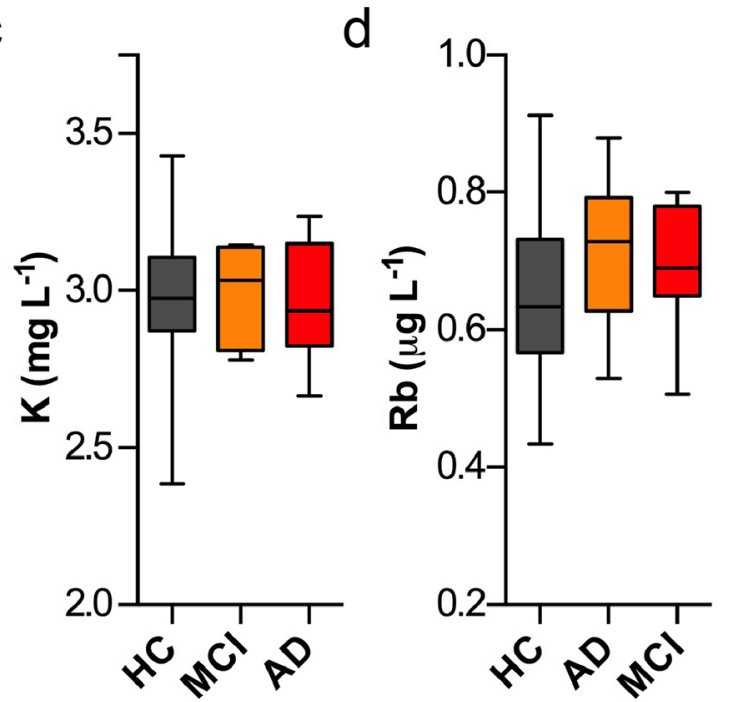

Fig. $3 \mathrm{~K}$ and $\mathrm{Rb}$ levels in platelets and CSF. a, b In platelets no significant changes were observed for $K$, though $\mathrm{Rb}$ was significantly decreased ( $p<0.01$; one-way ANOVA) in AD subjects compared to controls. $\mathbf{c}$, $\mathbf{d} \mathrm{K}$ and $\mathrm{Rb}$ levels in CSF remained unchanged. Boxes depict $25^{\text {th }}$ and $75^{\text {th }}$ percentiles and mean; error bars represent minimum to maximum values

Table 4 Subject demographics for platelets

\begin{tabular}{lllll}
\hline & $\begin{array}{l}\text { Healthy controls } \\
(n=50)\end{array}$ & $\begin{array}{l}\text { Mild cognitive } \\
\text { impairment } \\
(n=7)\end{array}$ & $\begin{array}{l}\text { Alzheimer's } \\
\text { disease } \\
(n=41)\end{array}$ & $p$-value \\
\hline Age (years) & $73.8(6.3)$ & $71.6(4.8)$ & $80.8(7.8)$ & $<0.001$ \\
Females (\%) & 60 & 14.3 & 75.6 & $<0.01$ \\
$\begin{array}{l}\text { \% APOE \&4 } \\
\text { carriers }\end{array}$ & 20 & 28.6 & 75.6 & $<0.001$ \\
\hline
\end{tabular}

$\overline{p \text {-value calculated using a one-way ANOVA or chi-squared test for percentages }}$
Table 5 Subject demographics for CSF

\begin{tabular}{lllll}
\hline & $\begin{array}{l}\text { Healthy controls } \\
(n=36)\end{array}$ & $\begin{array}{l}\text { Mild cognitive } \\
\text { impairment } \\
(n=7)\end{array}$ & $\begin{array}{l}\text { Alzheimer's } \\
\text { disease } \\
(n=9)\end{array}$ & $p$-value \\
\hline Age (years) & $71.8(5.6)$ & $68.3(4.5)$ & $71.3(7.1)$ & 0.40 \\
$\begin{array}{l}\text { Females (\%) } \\
58.0\end{array}$ & 57.1 & 33.3 & 0.41 \\
$\begin{array}{l}\text { \% APOE } \varepsilon 4 \\
\text { carriers }\end{array}$ & 19 & 0 & 44.4 & 0.20 \\
\hline
\end{tabular}

$p$-value calculated using a one-way ANOVA or chi squared test for percentages

PS2-APP and human tau expressing transgenic mice lines, $A P O E$ knockout and APOE4 knock-in mice showed no evidence of BBB permeability compared to both wild type and a positive multiple sclerosis model control using multiple assays, including $\mathrm{Rb}-86$ radiotracer experiments [36], questioning the long-held belief that BBB disruption is characteristic of $\mathrm{AD}$.

Receiver-operating characteristic curve analysis of brain $\mathrm{Rb}$ levels (Fig. 2f) shows that changes in levels of this metal is a strong predictor of $\mathrm{AD}$, therefore Rubidium-82/ 86 PET imaging could be used to identify early-stage AD. Considering that alkali metal homeostasis is disrupted via decreased $\mathrm{Na}^{+} / \mathrm{K}^{+}$-ATPase activity prior to $A \beta$ plaque formation, this approach may have greater preclinical value than the contemporary method employing Pittsburgh compound-B to assess brain amyloid burden by PET [37]. However, if the $\mathrm{BBB}$ integrity is maintained in $\mathrm{AD}$, delivery of the imaging agent presents a challenge to use as a preclinical diagnostic tool. An intact BBB still demonstrates a small degree $(2.1 \%)$ of $\mathrm{Rb}$ uptake, though this is ten-fold less than typically observed in cases of brain tumors and associated BBB disruption [38]. Hyperosmolar BBB disruption via injection of $25 \%$ mannitol to the carotid artery has been shown to induce a temporary window for ${ }^{82} \mathrm{Rb}$ loading into the baboon brain [39], though the safety of this approach in humans remains untested beyond patients with pre-existing brain tumors. A non-invasive scanning ultrasound approach to temporarily open the BBB in the APP23 transgenic AD mouse model was shown to be effective in clearing accumulated $\mathrm{A} \beta$ [40], and a number of clinical trials testing the safety and efficacy of this approach, predominantly for drug delivery, are currently ongoing [41]. Development of a suitable BBB-permeable vehicle that releases $\mathrm{Rb}$ into the brain is an intriguing line of enquiry.

An alternative means to monitor brain $\mathrm{Rb}$ levels without the need to deliver an exogenous tracer uses the paramagnetic properties of the naturally occurring ${ }^{87} \mathrm{Rb}$ radioisotope, which accounts for approximately $28 \%$ of $\mathrm{Rb}$ in the natural environment. $T_{1}$ and $T_{2}$ relaxation times are well suited to magnetic resonance imaging using specialized coils, and this approach has been used to quantitatively assess $\mathrm{K}$ (using ${ }^{87} \mathrm{Rb}$ as a proxy) in the brains of ischemic rats [42, 43]. This approach uses 
chronic $\mathrm{Rb}$ loading via drinking water in the weeks preceding MRI scanning, which could be employed in a diagnostic workflow for $\mathrm{AD}$, though the use of high field strength (e.g., $7 \mathrm{~T}$ ) MRI systems may have the capacity to assess endogenous ${ }^{87} \mathrm{Rb}$ with sufficient sensitivity.

\section{Conclusions}

We have shown that $\mathrm{Rb}$ and $\mathrm{K}$ levels are consistently decreased across all cellular components in the AD frontal cortex, and altered to a lesser extent in the periphery. As $\mathrm{Rb}$ is readily exchangeable with $\mathrm{K}$, we hypothesize that this decrease is indicative of dysfunctional $\mathrm{Na}^{+} / \mathrm{K}^{+}$-ATPase activity, a pathological feature of $\mathrm{AD}$ that is representative of an internal energy crisis and precedes the formation of proteinaceous inclusions and neuron loss in the disease. Rubidium levels in the brain performed well in predicating $\mathrm{AD}$, and may represent a new avenue of early diagnosis using existing in vivo imaging techniques, including PET and MRI.

\section{Additional file}

Additional file 1: $\mathrm{ROC}$ analysis of $\mathrm{Rb} \& \mathrm{~K}$ levels in plasma (Figure $\mathrm{S} 1$ ) and platelets (Figure S2). (DOCX $1297 \mathrm{~kb}$ )

\section{Acknowledgements}

We wish to acknowledge the support of the Cooperative Research Centre (CRC) for Mental Health. The CRC programme is an Australian Government initiative. Tissues were received from the Victorian Brain Bank Network, supported by The University of Melbourne, Alfred Hospital, the Victorian Forensic Institute of Medicine, the National Health and Medical Research Council. We acknowledge funding from the Victorian Government's Operational Infrastructure Support Program and the Australian Research Council Linkage Projects Scheme (with Agilent Technologies). Partial support from the National Health and Medical Research Council and the Alzheimer's Drug Discovery Research Foundation.

\section{Authors' contributions}

BR conceived of the study, and participated in its design and coordination. $\mathrm{DH}, \mathrm{BR}, \mathrm{AB}$ wrote the paper. IR, DH, LYF, BR carried out metal measurements. $C L M, A B, C F, A R$ participated in the collection of AIBL samples. CAM participated in the collection and diagnosis of brain tissue. BR, DH, JD, LYF, CF participated in the study design and statistical analysis. ML, DH, BR, LYF, IR carried out sample preparation. All authors read and approved the final manuscript.

\section{Competing interests}

The authors declare that they have no competing interests.

\begin{abstract}
Author details
${ }^{1}$ The Florey Institute of Neuroscience, The University of Melbourne, Parkville, VIC, Australia. ${ }^{2}$ Cooperative Research Centre for Mental Health, Parkville, VIC, Australia. ${ }^{3}$ The Australian e-Health Research Centre, Herston, QLD, Australia. ${ }^{4}$ CSIRO Preventative Health Flagship, Molecular Science and Engineering, Parkville, VIC, Australia. ${ }^{5}$ Department of Anatomical Pathology, The Alfred Hospital, Melbourne, VIC, Australia. ${ }^{6}$ Department of Medicine, Central Clinical School, Monash University, Clayton, VIC, Australia. ${ }^{7}$ Elemental Bio-imaging Facility, University of Technology, Broadway, Sydney, NSW, Australia. ${ }^{8}$ https:// aibl.csiro.au/about/aibl-research-team.
\end{abstract}

Received: 15 September 2016 Accepted: 29 October 2016 Published online: 14 November 2016

\section{References}

1. Mattson MP. Pathways towards and away from Alzheimer's disease. Nature. 2004;430(7000):631-9.

2. Kamat PK, Kalani A, Rai S, Swarnkar S, Tota S, Nath C, Tyagi N. Mechanism of oxidative stress and synapse dysfunction in the pathogenesis of Alzheimer's disease: understanding the Therapeutics strategies. Mol Neurobiol. 2014;53(1):648-61.

3. Butterfield D. Amyloid $\beta$-peptide (1-42)-induced oxidative stress and neurotoxicity: implications for neurodegeneration in Alzheimer's disease brain. A review. Free Radic Res. 2002;36(12):1307-13.

4. Crews L, Masliah E. Molecular mechanisms of neurodegeneration in Alzheimer's disease. Hum Mol Genet. 2010;19(R1):R12-20.

5. Angelova PR, Abramov AY. Alpha-synuclein and beta-amyloid - different targets, same players: calcium, free radicals and mitochondria in the mechanism of neurodegeneration. Biochem Biophys Res Commun. 2016.

6. Fukuyama H, Ogawa M, Yamauchi H, Yamaguchi S, Kimura J, Yonekura Y, Konishi J. Altered cerebral energy metabolism in Alzheimer's disease: a PET study. J Nucl Med. 1994;35(1):1-6.

7. Göbel B, Oltmanns KM, Chung M. Linking neuronal brain activity to the glucose metabolism. Theor Biol Med Model. 2013;10(1):50.

8. Astrup J, Sørensen PM, Sørensen HR. Oxygen and glucose consumption related to $\mathrm{Na}+-\mathrm{K}+$ transport in canine brain. Stroke. 1981;12(6):726-30.

9. Relman AS. The physiological behavior of rubidium and cesium in relation to that of potassium. Yale J Biol Med. 1956;29(3):248-62.

10. Fieve RR, Meltzer H, Dunner DL, Levitt M, Mendlewicz J, Thomas A. Rubidium: biochemical, behavioral, and metabolic studies in humans. Am J Psychiatry. 1973;130(1):55-61.

11. Tomlinson S, Mathialagan PD, Maloney SK. Special K: testing the potassium link between radioactive rubidium (86Rb) turnover and metabolic rate. J Exp Biol. 2013.

12. Vanhoe H, Vandecasteele C, Versieck J, Dams R. Determination of iron, cobalt, copper, zinc, rubidium, molybdenum, and cesium in human serum by inductively coupled plasma mass spectrometry. Anal Chem. 1989;61 (17):1851-7.

13. Gerhardsson L, Lundh T, Minthon L, Londos E. Metal concentrations in plasma and cerebrospinal fluid in patients with Alzheimer's disease. Dement Geriatr Cogn Disord. 2008;25(6):508-15.

14. Vance DE, Ehmann WD, Markesbery WR. A search for longitudinal variations in trace element levels in nails of Alzheimer's disease patients. Biol Trace Elem Res. 1990;26-27(1):461-70.

15. Basun H, Forssell LG, Wetterberg L, Winblad B. Metals and trace elements in plasma and cerebrospinal fluid in normal aging and Alzheimer's disease. J Neural Transm Park Dis Dement Sect. 1991;3(4):231-58.

16. Cornett CR, Ehmann WD, Wekstein DR, Markesbery WR. Trace elements in Alzheimer's disease pituitary glands. Biol Trace Elem Res. 1998;62(1-2):107-14.

17. Cornett CR, Markesbery WR, Ehmann WD. Imbalances of trace elements related to oxidative damage in Alzheimer's disease brain. Neurotoxicology. 1998;19(3):339-45

18. Ellis KA, Bush Al, Darby D, De Fazio D, Foster J, Hudson P, Lautenschlager NT, Lenzo N, Martins RN, Maruff P, et al. The Australian Imaging, Biomarkers and Lifestyle (AIBL) study of aging: methodology and baseline characteristics of 1112 individuals recruited for a longitudinal study of Alzheimer's disease. Int Psychogeriatr. 2009;21(4):672-87.

19. Rembach A, Hare DJ, Lind M, Fowler CJ, Cherny RA, McLean C, Bush Al, Masters $\mathrm{CL}$, Roberts BR. Decreased copper in Alzheimer's disease brain is predominantly in the soluble extractable fraction. Int J Alzheimers Dis. 2013;2013(1-2):1-7.

20. Roberts BR, Hare DJ, McLean CA, Conquest A, Lind M, Li Q-X, Bush Al, Masters CL, Morganti-Kossmann M-C, Frugier T. Traumatic brain injury induces elevation of $\mathrm{Co}$ in the human brain. Metallomics. 2015:7(1):124-8

21. Rembach A, Hare DJ, Doecke JD, Burnham SC, Volitakis I, Fowler CJ, Cherny RA, McLean C, Grimm R, Martins R, et al. Decreased serum zinc is an effect of ageing and not Alzheimer's disease. Metallomics. 2014;6(7):1216-9.

22. Rembach A, Evered LA, Li Q-X, Nash T, Vidaurre L, Fowler CJ, Pertile KK, Rumble RL, Trounson BO, Maher S, et al. Alzheimer's disease cerebrospinal fluid biomarkers are not influenced by gravity drip or aspiration extraction methodology. Alzheimers Res Ther. 2015;7(1):1.

23. Wenstrup D, Ehmann WD, Markesbery WR. Trace element imbalances in isolated subcellular fractions of Alzheimer's disease brains. Brain Res. 1990;533(1):125-31.

24. Bélavári C, Andrási E, Molnár Z, Bertalan É. Determination of alkali metals in control and $\mathrm{AD}$ brain samples by different techniques. Microchem J. 2005;79(1-2):367-73. 
25. Miller JA, Woltjer RL, Goodenbour JM, Horvath S, Geschwind DH. Genes and pathways underlying regional and cell type changes in Alzheimer's disease. Genome Med. 2013;5(5):1.

26. Yu SP, Farhangrazi ZS, Ying HS, Yeh C-H, Choi DW. Enhancement of outward potassium current May participate in $\beta$-amyloid peptide-induced cortical neuronal death. Neurobiol Dis. 1998:5(2):81-8.

27. Arispe N, Pollard HB, Rojas E. Giant multilevel cation channels formed by Alzheimer disease amyloid beta-protein [A beta P-(1-40)] in bilayer membranes. Proc Natl Acad Sci U S A. 1993;90(22):10573-7.

28. Liang WS, Reiman EM, Valla J, Dunckley T, Beach TG, Grover A, Niedzielko TL, Schneider LE, Mastroeni D, Caselli R, et al. Alzheimer's disease is associated with reduced expression of energy metabolism genes in posterior cingulate neurons. Proc Natl Acad Sci U S A. 2008;105(11):4441-6.

29. Hashimoto RF, Kim S, Shmulevich I, Zhang W, Bittner ML, Dougherty ER. Growing genetic regulatory networks from seed genes. Bioinformatics. 2004;20(8):1241-7.

30. Caberlotto L, Lauria M, Nguyen T-P, Scotti M. The central role of AMP-kinase and energy homeostasis impairment in Alzheimer's disease: a multifactor network analysis. PLoS One. 2013;8(11), e78919.

31. Howarth C, Gleeson P, Attwell D. Updated energy budgets for neural computation in the neocortex and cerebellum. J Cereb Blood Flow Metab. 2012;32(7):1222-32.

32. Hattori N, Kitagawa K, Higashida T, Yagyu K, Shimohama S, Wataya T, Perry G, Smith MA, Inagaki C. Cl--ATPase and Na+/K +-ATPase activities in Alzheimer's disease brains. Neurosci Lett. 1998;254(3):141-4.

33. Chauhan NB, Lee JM, Siegel GJ. Na, K-ATPase mRNA levels and plaque load in Alzheimer's disease. J Mol Neurosci. 1997;9(3):151-66.

34. Roelcke U, Radü EW, von Ammon K, Hausmann O, Maguire RP, Leenders KL. Alteration of blood-brain barrier in human brain tumors: comparison of [18 F]fluorodeoxyglucose, [11C]methionine and rubidium-82 using PET. J Neurol Sci. 1995;132(1):20-7.

35. Marques F, Sousa JC, Sousa N, Palha JA. Blood-brain-barriers in aging and in Alzheimer's disease. Mol Neurodegener. 2013;8(1):1.

36. Bien-Ly N, Boswell CA, Jeet S, Beach TG, Hoyte K, Luk W, Shihadeh V, Ulufatu S, Foreman O, Lu Y, et al. Lack of widespread BBB disruption in Alzheimer's disease models: focus on therapeutic antibodies. Neuron. 2015; 88(2):289-97.

37. Klunk WE, Engler $H$, Nordberg A, Wang Y, Blomqvist G, Holt DP, Bergström $M$, Savitcheva I, Huang G-F, Estrada S, et al. Imaging brain amyloid in Alzheimer's disease with Pittsburgh Compound-B. Ann Neurol. 2004;55(3):306-19.

38. Brooks DJ, Beaney RP, Lammertsma AA, Leenders KL, Horlock PL, Kensett MJ, Marshall J, Thomas DG, Jones T. Quantitative measurement of blood — brain barrier permeability using rubidium-82 and positron emission tomography. J Cereb Blood Flow Metab. 1984:4(4):535-45.

39. Zünkeler B, Carson RE, Olson J, Blasberg RG, Girton M, Bacher J, Herscovitch P, Oldfield EH. Hyperosmolar blood-brain barrier disruption in baboons: an in vivo study using positron emission tomography and rubidium-82. J Neurosurg. 1996;84(3):494-502

40. Leinenga G, Götz J. Scanning ultrasound removes amyloid- $\beta$ and restores memory in an Alzheimer's disease mouse model. Sci Transl Med. 2015; 7(278):278ra233

41. Leinenga G, Langton C, Nisbet R, Götz J. Ultrasound treatment of neurological diseases - current and emerging applications. Nat Rev Neurol. 2016;12(3):161-74.

42. Yushmanov VE, Kharlamov A, Ibrahim TS, Zhao T, Boada FE, Jones SC. K+ dynamics in ischemic rat brain in vivo by $87 \mathrm{Rb}$ MRI at $7 \mathrm{~T}$. NMR Biomed. 2011;24(7):778-83.

43. Yushmanov VE, Kharlamov A, Boada FE, Jones SC. Monitoring of brain potassium with rubidium flame photometry and MRI. Magn Reson Med. 2007;57(3):494-500.

\section{Submit your next manuscript to BioMed Central and we will help you at every step:}

- We accept pre-submission inquiries

- Our selector tool helps you to find the most relevant journal

- We provide round the clock customer support

- Convenient online submission

- Thorough peer review

- Inclusion in PubMed and all major indexing services

- Maximum visibility for your research

Submit your manuscript at www.biomedcentral.com/submit
Biomed Central 